\title{
Understanding the Relationship Between Students' Mathematics Anxiety Levels and Mathematics Performances at the Foundation Level
}

\author{
Emmerline Shelda Siaw ${ }^{1}$, George Tan Geok Shim ${ }^{1}$, Farah Liyana Azizan ${ }^{1}$ \& Norhunaini Mohd Shaipullah ${ }^{1}$ \\ ${ }^{1}$ Centre for Pre-University Studies, University Malaysia Sarawak, Sarawak, Malaysia \\ Correspondence: Emmerline Shelda Siaw, Centre for Pre-University Studies, University Malaysia Sarawak, \\ Sarawak, Malaysia. E-mail: seshelda@unimas.my
}

Received: November 3, 2020 Accepted: December 13, 2020 Online Published: December 30, 2020

doi:10.5539/jel.v10n1p47 URL: https://doi.org/10.5539/jel.v10n1p47

\begin{abstract}
For many students, mathematics is regarded as a challenging subject to learn and master in class. One of the significant factors contributing to the students' difficulties in learning mathematics is caused by a phenomenon called mathematics anxiety. Mathematics anxiety is a feeling of unease and anxiety toward mathematics and it can be different from person-to-person. Understanding the effects of mathematics anxiety levels on students' mathematics performances in class can be the key to help students' mastery of mathematics. The aim of the study is to investigate the relationship between mathematics anxiety levels and students' mathematics performances at the foundation level. A sample of 545 students from a local foundation centre was chosen for this study. Data collection via questionnaire was used where quantitative data were analysed using correlation, t-test, and descriptive analyses. The results showed that there was a weak positive correlation between students' anxiety levels and the students' mathematics performance in their final examination. Recommendations and future potential for this study were further discussed in this paper.
\end{abstract}

Keywords: mathematics, mathematics anxiety, foundation level, mathematics performances

\section{Introduction}

\subsection{Introduction}

Students' proficiency and mastery in mathematics today have become one of the major focuses among educators especially with the rise of awareness in Science, Technology, Engineering and Mathematics (STEM) education and Education 4.0. Mathematics is a fundamental subject in education that encourages the development of learners' thinking ability. According to Cresswell and Speelman (2020), learning and mastery of mathematics can facilitate logical, analytical, critical, and abstract thinking among students. Mathematics offers fundamental skills such as thinking in life, establishing relationships between events, reasoning, estimating, problem-solving apart from gaining calculation skills and teaching numbers and mathematical operation (Umay, 2003; cited in Onal, Inan, \& Bozkurt, 2017). Besides that, mathematics also provides a supportive role in understanding and mastering other sciences and art subjects. Hence, it is crucial for educators to understand the learners' barriers in learning mathematics, as it is common for students to have negative perceptions towards mathematics (Ashcraft, 2002).

Mathematics anxiety is known to be one of the major factors that hinders the students' proficiency and mastery in mathematics. According to Yeo, Tan and Lew (2015), anxiety in mathematics is one of the categories of uneasiness and may have a negative impact on students as it is continually presented within mathematical problems. Mathematics anxiety occurs within all levels of education and continues to rise as the year progresses (Yurtcu \& Dogan, 2003). The level of mathematics anxiety in students can also be an honest indicator of students' academic success (Karimi \& Venkatesh, 2010). A study by Sheffield and Hunt (2006) found that students with high mathematics anxiety levels generally performed low in their mathematics assessments. Understanding the nature of mathematics anxiety and its effects on students' behaviour may provide an insight on how to minimize and manage mathematics anxiety among students.

With the foundation level acting as a bridge between secondary and tertiary level education, it is interesting to explore the effects of mathematics anxiety on students' mathematics achievements and their behaviour at this 
level. Hence, the study aimed to investigate the relationship between mathematics anxiety level and students' mathematics performances at the foundation level. Besides that, the study investigated students' mathematics anxiety based on the program of their study and their behaviour when dealing with mathematics. This paper is structured as follows: Section 1 discusses the overview of the study that includes the literature review of mathematics anxiety, reviews of past studies on mathematics anxiety, and an explanation of the objectives of this study. Meanwhile, Section 2 describes the methodology of this study that consists of samples, instruments, and methods. Section 3 presents the finding of the study. Next, Section 4 discusses the results and limitations of this study. Finally, Section 5 summarizes the project and offers future research opportunities.

\subsection{What Is Mathematics Anxiety?}

Tobias and Weissbrod (1980, as cited in Fiore, 1999) defined mathematical anxiety as fear, hopelessness, paralysis, and mental disorientation that emerges among some individuals when mathematical problem solving is needed. It is a condition of a decline in feelings, confusion, and frustration in mathematical thinking and understanding (Pradeep, 2011). Khatoon and Mahmood (2010) stated that mathematical anxiety also contributes to a person's feelings of discomfort and anxiety which interfere with number manipulation and mathematical problem-solving in a wide range of ordinary and academic settings. Furthermore, mathematics anxiety can be characterised as the emotional reaction of a person, which can affect mathematics learning achievement. In this situation, the individual's negative emotional reaction to mathematics is seen as a factor that affects the learning outcome of low mathematics (Udil, Kusmayadi, \& Riyadi, 2017).

There are environmental factors that promote the development of mathematics anxiety such as the ways teachers approach the students in the class, the mindset of parents toward their children's ability in mathematics, societal patterns or personal factors such as traits or gender (Paechter, Macher, Martskvishvili, Wimmer, \& Papousek, 2017). These aspects may affect the crucial variables in the learning process of a learner. Studies have also found that nervousness and discomfort among high school students caused by mathematics happen when students do not feel self-confidence (Escalera-Chávez, 2016). Mathematics anxiety takes an immediate effect in mathematics-related situations in everyday experiences as well as evaluative classroom situations such as answering a question in front of their peers, examinations, or any other learning assessments in the classroom (Ramirez, Hooper, Kersting, Ferguson, \& Yeager, 2018). Ching (2017) stated that mathematics anxiety is an important issue and a barrier that learners must overcome as it influences students' achievement in mathematics. Poor mathematics performances among students do not necessarily reflect the students' failure to grasp mathematics concepts as anxiety towards mathematics may interfere with students' ability to solve the mathematics problems (Blazer, 2018).

\subsection{Past Studies on Mathematics Anxiety}

Many studies have been conducted on the effects of mathematics anxiety on students' mathematical behaviour and achievements. Kangar, Tarmizi and Bayat's (2010) study showed that there was a negative relationship between mathematical anxiety, mathematics thinking and mathematics attitudes, where students with high mathematics anxiety levels performed low in both their mathematical thinking and mathematical attitudes. On the other hand, students with low mathematics anxiety levels performed higher in both of their mathematical thinking and mathematical attitudes. The study agreed that the improvement in students' mathematical thinking and attitudes could be made if the students' mathematics anxiety were reduced (Kangar et al., 2010).

Karimi and Venkatesh's (2010) study on mathematics anxiety, mathematics performance, and overall academic performance in Indian high school also showed that mathematics anxiety has a negative correlation on both students' mathematics performances and their overall academic performance. Moreover, the study also showed that there was no correlation between students' mathematics anxiety and academic hardiness. The study also highlighted that there were significant gender differences in mathematics anxiety, with female students having a slightly higher level of anxiety compared to male students.

The relation between mathematics anxiety and metacognitive comprehension was established by Hoorfah and Taleb (2015). 16.5 percent of their seventh-grade female students were chosen randomly by this analysis as the sample. The validated Persian version of the structured Chiu and Henry's Math Anxiety Scale questionnaires and the metacognitive abilities of Swanson were used. There was a correlation, they said, between low math anxiety and higher cognitive knowledge.

However, Seng (2015) study found that there was a positive relationship between mathematics anxiety and numerical anxiety on students' mathematical performances, where students' anxiety prior to an examination showed better results in their mathematics achievements, compared to students' anxiety post examination, during quizzes, or while solving challenging mathematical problems. In addition, the study also found that students' 
anxiety in daily life's application was the highest compared to students' anxiety in four basic operations in numerical anxiety (Seng, 2015). Therefore, higher levels of mathematics anxiety among the students are linked to lower performance in school or college tests or assessments with various factors (Pantoja et al., 2020) and current research reveals that the mathematics anxiety and mathematics performance link is associated with both individual factors (cognitive, affective/physiological, motivational) and environmental (social/contextual) factors (Chang \& Beilock, 2016).

\subsection{Objectives of the Study}

The objectives of the study are as follows:

- To investigate the relationship between mathematics anxiety and the students' performance in mathematics.

- To investigate the students' mathematics anxiety levels based on the programs of study.

- To examine students' behaviour towards mathematics.

\section{Methodology}

\subsection{Samples}

The samples of the study consisted of 545 students from a foundation centre in Malaysia. Samples were randomly selected from two (2) different programs in the foundation centre, which are the Life Sciences (LS) and Physical Sciences (PS) program. The two programs shared a majority of the same courses, curriculums, academic staff, and facilities, with one exception, where only Life science program has a Biology course while only Physical science program has a physics course. In addition, all students have the same minimum entry requirements for both programs, ensuring that all students generally have the same skills and knowledge needed for the foundation level.

\subsection{Instrument}

The data for this study were collected via questionnaires. The online survey was used to elicit students' responses. The questionnaire for this study consisted of two sections, Section A and Section B. Section A of the questionnaire was adapted from Hunt, Carter, and Sheffield's (2011) revised version of the Mathematics Anxiety Scale-UK (MAS-UK). It comprised of 23 items concerning situations involving mathematics and students were required to indicate their level of anxiousness based on a 5-point Likert scale (1-Not at all, 2-Slightly, 3-A fair amount, 4-Much and 5-Very much). Table 1 shows the examples of the items in Section A of the questionnaire.

Table 1. Examples of items in section A of the questionnaire

\begin{tabular}{ll}
\hline No. & Items \\
\hline 1. & Having someone watch you multiply $12 \times 23$ on paper \\
2. & Adding up a pile of coins \\
3. & Being asked to write an answer on the whiteboard in front of Mathematics class \\
4. & Being asked to add up the number of people in a room \\
5. & Calculating how many days until a person's birthday \\
6. & Taking a Mathematics exam \\
7. & Being asked to divide RM 9.36 by 4 in front of several people \\
8. & Being given a telephone number and having to remember it \\
9. & Reading the word "trigonometry" \\
10. & Calculating a series of multiplication problems on paper \\
\hline
\end{tabular}

Section B of the questionnaire comprised of ten (10) items that involved students' behaviour when dealing with mathematics in and outside of the class. Similarly, students were required to respond to the items based on a 5-point Likert scale (1-Never, 2-Seldom, 3-Sometimes, 4-Often, and 5-Usually). Pilot testing was done on a group of seventeen college students who were at the same level of study. The Cronbach's alpha value for this scale is 0.875 , indicating a high level of internal consistency. Table 2 shows the 10 items in Section B of the questionnaire. 
Table 2. Items in section $\mathrm{B}$ of the questionnaire

\begin{tabular}{ll}
\hline No & Items \\
\hline 1. & I watch online videos related to Mathematics. \\
2. & I use an application to help me solve Mathematics solution such as Wolfram. \\
3. & My family members help me to solve Mathematics questions at home. \\
4. & I really need extra classes for Mathematics subject. \\
5. & I hope the lecturer would give me more exercises outside of the classroom. \\
6. & I prefer a smaller Mathematics class. \\
7. & I cannot relate the application of Mathematics in other subjects such as Chemistry, Biology, and Physics. \\
8. & I do not like my Mathematics class. \\
9. & I feel anxious when my friends get better results in Mathematics. \\
10. & I try to find all the solutions to tutorial questions before the discussion in class happens. \\
\hline
\end{tabular}

\subsection{Method}

Questionnaires were distributed to the randomly selected students at the end of the 2nd Semester for the foundation study. Students were instructed to complete the questionnaire within 30 minutes and they were told to submit their questionnaires upon completion. In addition, the students' final mathematics assessment score was also collected from the mathematics course coordinator.

In order to explore the link of mathematical anxiety and mathematical achievement, current research has used quantitative approaches. The structure of this analysis may be the relation between these two variables. Figure 1 shows mathematics test anxiety in section A and B contributes to anxiety in mathematics. How programs respond to mathematics anxiety and the impact of mathematics anxiety on students' achievement in mathematics also shown in the figure below.

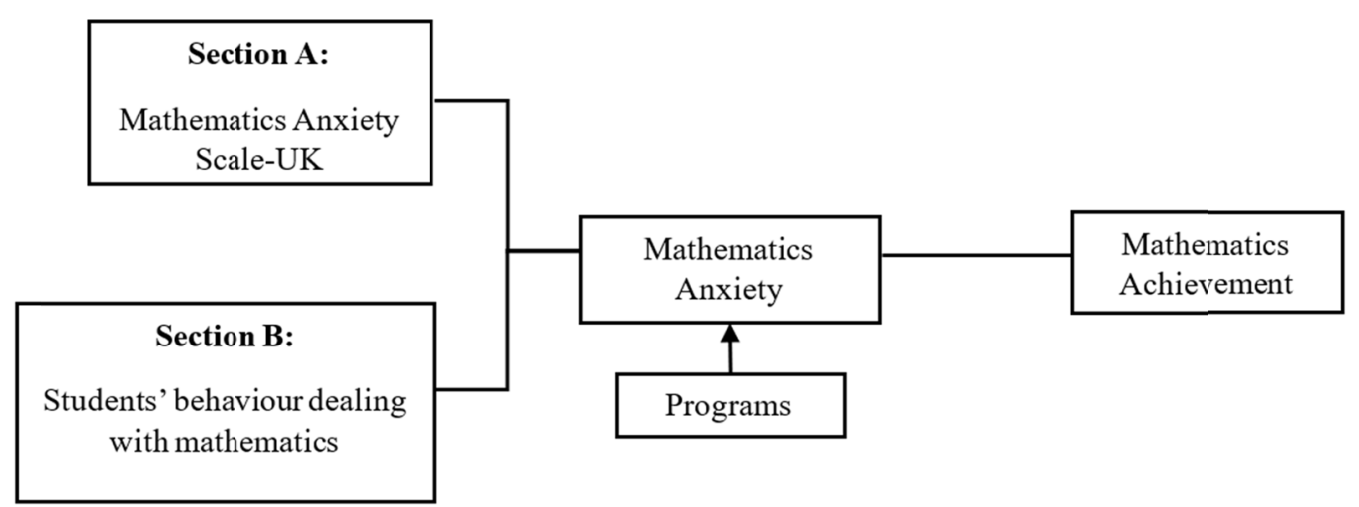

Figure 1. Theoretical framework

Data collected from the questionnaire and the students' final mathematics assessment score were input in the IBM SPSS Statistics program where the data were analysed via Person Correlation, t-test and descriptive analyses.

\section{Findings of the Study}

\subsection{Relationship Between Mathematics Anxiety and the Students' Performance in Mathematics.}

Table 3. The mean and standard deviation of students' anxiety levels and students' performance in the final examination

\begin{tabular}{llll}
\hline & Mean & Std. Deviation & $\mathrm{N}$ \\
\hline Anxiety & 2.83 & 0.713 & 545 \\
Final Examination & 4.39 & 2.209 & 545 \\
\hline
\end{tabular}


Table 4. Pearson correlation results between students' anxiety levels and students' mathematics performance in the final examination

\begin{tabular}{llll}
\hline & & Anxiety & Final Examination \\
\hline Anxiety & Pearson Correlation & 1 & $0.134^{* *}$ \\
& Sig. (2-tailed) & & 0.002 \\
& $\mathrm{~N}$ & 545 & 545 \\
Final Examination & Pearson Correlation & $0.134^{* *}$ & 1 \\
& Sig. (2-tailed) & 0.002 & \\
& $\mathrm{~N}$ & 545 & 545 \\
\hline
\end{tabular}

Note. ${ }^{* *}$. Correlation is significant at the 0.01 level (2-tailed).

Tables 3 and 4 show the mean, standard deviation, and Pearson correlation between the students' anxiety levels and students' performance in the final examination. Based on the Tables 3 and 4, it shows that there was a positive weak correlation between students' anxiety levels (Mean $=2.83, \mathrm{SD}=0.713$ ) and the students' mathematics performance in the final examination (Mean $=4.39, \mathrm{SD}=2.209$ ), with $\mathrm{r}=0.134, \mathrm{p} \leq 0.005, \mathrm{~N}=$ 545. Thus, the increase in students' mathematics anxiety levels can contribute to the increased performance in their mathematics final examination.

\subsection{Students' Mathematics Anxiety Based on the Program of Study}

Table 5. Independent t-test comparing students' mathematics anxiety levels in the program of study

\begin{tabular}{|c|c|c|c|c|c|c|c|c|c|c|}
\hline & & \multirow[t]{2}{*}{$\mathrm{F}$} & \multirow[t]{2}{*}{ Sig. } & \multirow[t]{2}{*}{$\mathrm{t}$} & \multirow[t]{2}{*}{$\mathrm{df}$} & \multirow[t]{2}{*}{$\begin{array}{l}\text { Sig. } \\
\text { (2-tailed) }\end{array}$} & \multirow[t]{2}{*}{$\begin{array}{l}\text { Mean } \\
\text { Difference }\end{array}$} & \multirow[t]{2}{*}{$\begin{array}{l}\text { Std. Error } \\
\text { Difference }\end{array}$} & \multicolumn{2}{|c|}{$\begin{array}{l}95 \% \text { Confidence Interval } \\
\text { of the Difference }\end{array}$} \\
\hline & & & & & & & & & Lower & Upper \\
\hline \multirow[t]{2}{*}{ Anxiety } & $\begin{array}{l}\text { Equal variances } \\
\text { assumed }\end{array}$ & 0.145 & 0.703 & 0.999 & 543 & 0.318 & 0.061 & 0.061 & -0.059 & 0.182 \\
\hline & $\begin{array}{l}\text { Equal variances } \\
\text { not assumed }\end{array}$ & & & 1.003 & 534.2 & 0.316 & 0.061 & 0.061 & -0.059 & 0.181 \\
\hline
\end{tabular}

Table 5 shows the independent t-test result comparing the students' mathematics anxiety levels in their program of study. Based on Table 5, it shows that there were no significant differences between Life sciences and Physical sciences students in their mathematics anxiety $(\mathrm{t}(543)=0.999, \mathrm{p}>0.05)$. Thus, different programs enrolled by students may not affect their mathematics anxiety levels in foundation studies.

\subsection{Students' Behaviour Towards Mathematics}

Table 6. Students' behaviour towards mathematics

\begin{tabular}{llll}
\hline No & Items & Mean & Standard Deviation \\
\hline 1. & I watch online videos related to Mathematics. & 3.018 & 1.213 \\
2. & I use an application to help me solve Mathematics solution such as Wolfram. & 2.554 & 1.277 \\
3. & My family members help me to solve Mathematics questions at home. & 2.176 & 1.104 \\
4. & I really need extra classes for Mathematics subject. & 3.222 & 1.163 \\
5. & I hope the lecturer would give me more exercises outside of the classroom. & 3.422 & 1.132 \\
6. & I prefer a smaller Mathematics class. & 3.749 & 1.118 \\
7. & I cannot relate the application of Mathematics in other subjects such as Chemistry, Biology, & 2.516 & 1.049 \\
& and Physics. & 1.917 & 0.952 \\
8. & I do not like my Mathematics class. & 3.644 & 1.189 \\
9. & I feel anxious when my friends get better results in Mathematics. & 3.794 & 1.006 \\
10. & I try to find all the solutions to tutorial questions before the discussion in class happens. \\
\hline
\end{tabular}

Table 6 shows the mean and the standard deviation of ten items on students' behaviour when studying mathematics. Based on Table 6, it shows that item 10: "I try to find all the solutions to tutorial questions before the discussion in class happens", has the highest positive response (Mean $=3.794, \mathrm{SD}=1.006$ ), followed by item 6: "I prefer a smaller Mathematics class" (Mean $=3.749, \mathrm{SD}=1.118)$, item 9: "I feel anxious when my friends get better results in Mathematics" (Mean $=3.644, \mathrm{SD}=1.189$ ), item 5: "I hope the lecturer would give me more exercises outside of the classroom" (Mean $=3.422, \mathrm{SD}=1.132)$, item 4: "I really need extra classes for 
Mathematics subject" $($ Mean $=3.222, \mathrm{SD}=1.163)$, item 1: "I watch online videos related to Mathematics" (Mean $=3.018, \mathrm{SD}=1.213)$, item 2: "I use an application to help me solve Mathematics solution such as Wolfram" (Mean $=3.018, \mathrm{SD}=1.213)$, item 7: "I cannot relate the application of Mathematics in other subjects such as Chemistry, Biology and Physics" (Mean = 2.516, SD =1.049), item 3: "My family members help me to solve Mathematics questions at home" (Mean $=2.176, \mathrm{SD}=1.104)$ and item 8: "I do not like my Mathematics class" (Mean $=1.917, \mathrm{SD}=0.952)$.

\section{Discussion and Limitations}

The findings showed that there was a weak positive correlation between students' anxiety levels and the students' mathematics performance in the final examination. It showed that students' mathematics anxiety levels did affect the students' performance in the final examination, where the increased level of students' mathematics anxiety would contribute to the increase of the students' mathematics performances in the final examination. In this case, students who have mathematics anxiety might be motivated and focused on improving their mathematics understanding in order to perform better in their mathematics final examination. The result of the study supported Seng's (2015) study, which also showed that there was a positive relationship between mathematics anxiety and numerical anxiety on students' mathematical performances. However, the result of the study contradicted Kangar et al. (2010) and Karimi and Venkatesh (2010), where both studies showed a negative relationship between mathematics anxiety and mathematics performance.

In addition, this study also showed that there was no significant difference between two different programs of study in their mathematics anxiety level. The results of the study highlighted that mathematics anxiety could occur to any student regardless of the program of their study. Hence, educators must be aware of the existence of mathematics anxiety in their students as its effects might vary depending on the students.

Several limitations have been identified in this study. The first limitation of the study is time constraint. As the students only have one year to finish their foundation studies, we did not have enough time to do any intervention in the class. Secondly, the data for this research were gathered using a measurement tool focused on Mathematics Anxiety-Scale-UK (MAS-UK). This implies that the collected data can only define the variables within the constraints of the measurement instruments. In the future study it is important to use different methods such as interviews, findings, peer review and intervention.

\section{Conclusion}

Mathematics anxiety is still an important topic in mathematics that can determine the outcome of the students' mathematics learning and achievements. This study has shown that there is a positive relationship between students' anxiety levels and students' performances in mathematics assessments. With the outcome of the study, it is hoped that more research will be conducted to further investigate the effects of mathematics anxiety, especially at the tertiary education level. Future studies possibility arising from studies includes a plan to examine students' strategies and suggestions in dealing with mathematics anxiety in class.

\section{Acknowledgment}

This research is fully supported by the Scholarship of Teaching and Learning Grant (SoTLG), SoTL/PPPU/2018(1)/001. The authors fully acknowledged Universiti Malaysia Sarawak for the approved fund which makes this important research viable and effective.

\section{References}

Ashcraft, M. H. (2002). Math anxiety: Personal, educational, and cognitive consequences. Current Directions in Psychological Science, 11(5), 181-185. https://doi.org/10.1111/1467-8721.00196

Blazer, C. (2011). Strategies for reducing math anxiety. Information Capsule, 1102, 1-8. Research Services, Miami-Dade County Public Schools. Retrieved from https://eric.ed.gov/?id=ED536509

Chang, H., \& Beilock, S. L. (2016). The math anxiety-math performance link and its relation to individual and environmental factors: A review of current behavioural and psychophysiological research. Current Opinion in Behavioral Sciences, 10, 33-38. https://doi.org/10.1016/j.cobeha.2016.04.011

Ching, B. H.-H. (2017). Mathematics anxiety and working memory: Longitudinal associations with mathematical performance in Chinese children. Contemporary Educational Psychology, 51, 99-113. https://doi.org/10.1016/j.cedpsych.2017.06.006

Cresswell, C., \& Speelman, C. P. (2020). Does mathematics training lead to better logical thinking and reasoning? A cross-sectional assessment from student to professors. PLoS ONE, 15(7), e0236153. https://doi.org/10.1371/journal.pone.0236153 
Escalera-Chávez, M. E., Moreno-García, E., García-Santillán, A., \& Rojas-Kramer, C. A. (2016). Factors that promote anxiety toward math on high school students. Eurasia Journal of Mathematics, Science and Technology Education, 13(1), 189-199. https://doi.org/10.12973/eurasia.2017.00611a

Fiore, G. (1999). Math abused students: Are we prepared to teach them? Math Teacher, 92(5), 403-406. https://doi.org/10.5951/MT.92.5.0403

Hoorfah, H., \& Taleb, Z. (2015). Correlation between mathematics anxiety with metacognitive knowledge. Procedia Social and Behavioral Sciences, 182, 737-741. https://doi.org/10.1016/j.sbspro.2015.04.822

Hunt, T. E., Carter, D. C., \& Sheffield, D. (2011). The development and part validation of a U.K. scale for mathematics anxiety. Journal of Psychoeducational Assessment, 29(5), 455-466. https://doi.org/10.1177/0734282910392892

Kangar, M., Tarmizi, R. A., \& Bayat, S. (2010). Relationship between Mathematical Thinking, Mathematics Anxiety and Mathematics Attitudes among University Students. Procedia Social and Behavioral Sciences, 8, 537-542. https://doi.org/10.1016/j.sbspro.2010.12.074

Karimi, A., \& Venkatesh, K. G. (2010). Mathematics anxiety, mathematics performance and overall academic performance in high school students. Journal of the Indian Academy of Applied Psychology, 36(1), 147-150. https://doi.org/10.1177/0258042X0903400406

Khatoon, T., \& Mahmood, S. (2010). Mathematics anxiety among secondary school students in India and its relationship to achievement in mathematics. European Journal of Social Sciences, 16(1), 75-86.

Onal, H., Inan, M., \& Bozkurt, S. (2017). A Research on Mathematical Thinking Skills: Mathematical Thinking Skills of Athletes in Individual and Team Sports. Journal of Education and Training Studies, 5(9), 133-139. http://dx.doi.org/10.11114/jets.v5i9.2428

Paechter, M., Macher, D., Martskvishvili, K., Wimmer, S., \& Papousek, I. (2017). Mathematics anxiety and statistics anxiety. Shared but also unshared components and antagonistic contributions to performance in statistics. Frontiers in Psychology, 8, 1196. https://doi.org/10.3389/fpsyg.2017.01196

Pantoja, N., Schaeffer, M. W., Rozek, C. S., Beilock, S. L., \& Levine, S. C. (2020). Children's Math Anxiety Predicts Their Math Achievement Over and Above a Key Foundational Math Skill. Journal of Cognition and Development, 1-20. https://doi.org/10.1080/15248372.2020.1832098

Pradeep, R. (2011). A study of mathematics anxiety amongst primary pre-service teachers enrolled in a Dutch teacher training program. Master Thesis: Universiteit van Amsterdam.

Ramirez, G., Hooper, S. Y., Kersting, N. B., Ferguson, R., \& Yeager, D. (2018). Teacher math anxiety relates to adolescent students' math achievement. AERA Open, 4(1). https://doi.org/10.1177/2332858418756052

Seng, E. L. K. (2015). The Influence of Pre-University Students' Mathematics Test Anxiety and Numerical Anxiety on Mathematics Achievement. International Education Studies, 8(11), 162. https://doi.org/10.5539/ies.v8n11p162

Sheffield, D., \& Hunt, T. (2006). How does anxiety influence maths performance and what can we do about it? MSOR (Maths, Stats \& OR Network) Connections, 6(4), 19-23. https://doi.org/10.11120/msor.2006.06040019

Tsanwani, A. R. (2009). Tracing factors that facilitate achievement in mathematics in traditionally disadvantaged secondary schools. Ph.D. thesis: University of Pretoria. Retrieved from https://repository.up.ac.za/bitstream/handle/2263/24976/Complete.pdf? sequence=10

Udil, A. P., Kusmayadi, T. A., \& Riyadi. (2017). Profile of mathematics anxiety of 7th graders. Proceeding the 4th International Conference on Research, Implementation, and Education of Mathematics and Science (4th ICRIEMS). https://doi.org/10.1063/1.4995144

Yeo, W. L., Tan, C. K., \& Lew, S. L. (2015). Mathematics Anxiety among Male and Female Students. International Journal of Psychological and Behavioral Sciences, 9(8), 2830-2835.

Yurtcu, M., \& Dogan, N. (2015). Scaling with Paired Comparison Method for Reasons for Mathematics Anxiety of Secondary School Students. Procedia Social and Behavioral Sciences, 197, 851-857. https://doi.org/10.1016/j.sbspro.2015.07.209 


\section{Copyrights}

Copyright for this article is retained by the author, with first publication rights granted to the journal.

This is an open-access article distributed under the terms and conditions of the Creative Commons Attribution license (http://creativecommons.org/licenses/by/4.0/). 